\title{
A DAMPING CONSTANT LIMITATION DESIGN OF POWER SYSTEM STABILIZER USING HYBRID DIFFERENTIAL EVOLUTION
}

\author{
Yung-Sung Chuang \\ Lecture, Department of Electrical Engineering, Ming-Hsin University of Science and Technology. \\ Chi-Jui Wu \\ Professor, Department of Electrical Engineering, National Taiwan University of Science and Technology, Taipei, \\ Taiwan, R.O.C., cjwu@mouse.ee.ntust.edu.tw
}

Follow this and additional works at: https://jmstt.ntou.edu.tw/journal

Part of the Electrical and Computer Engineering Commons

\section{Recommended Citation}

Chuang, Yung-Sung and Wu, Chi-Jui (2006) "A DAMPING CONSTANT LIMITATION DESIGN OF POWER SYSTEM STABILIZER USING HYBRID DIFFERENTIAL EVOLUTION," Journal of Marine Science and Technology. Vol. 14: Iss. 2, Article 3.

DOI: $10.51400 / 2709-6998.2061$

Available at: https://jmstt.ntou.edu.tw/journal/vol14/iss2/3

This Research Article is brought to you for free and open access by Journal of Marine Science and Technology. It has been accepted for inclusion in Journal of Marine Science and Technology by an authorized editor of Journal of Marine Science and Technology. 
A DAMPING CONSTANT LIMITATION DESIGN OF POWER SYSTEM STABILIZER USING HYBRID DIFFERENTIAL EVOLUTION

Acknowledgements

This paper is supported partly by the National Science Council of ROC, NSC 93-2213-E-011-082. 


\title{
A DAMPING CONSTANT LIMITATION DESIGN OF POWER SYSTEM STABILIZER USING HYBRID DIFFERENTIAL EVOLUTION
}

\author{
Yung-Sung Chuang* and Chi-Jui Wu**
}

Key words: power system stabilizer, power system stability, excitation system, hybrid differential evolution, optimization.

\section{ABSTRACT}

This paper is used to investigate a novel design of lead-lag type power system stabilizers for a multi-machine power system. In the design procedures, the minimum damping constants requirements of all of electromechanical modes can be designated and several typical operating conditions can be considered at the same time. The hybrid differential evolution (HDE) method is used to tune the parameters of power system stabilizers. In the design procedures, a region in the left half complex plane bounded by a line with a given negative real value is given. Thus, at the final step of the HDE, all of electromechanical modes should be moved to or near this region to have a smaller objective function value. In this paper, the objective function is chosen to let the design results have small real parts of electromechanical modes. Since the speed deviations are used as the feedback signals of the power system stabilizers, the stabilizers could be implemented easily. Because several operating conditions are considered in the design of stabilizer parameter values, the damping forces are ensured effective in those operating conditions simultaneously. Nonlinear system time domain simulations are used to demonstrate the design results.

\section{INTRODUCTION}

The dynamic stability characteristics of a power system are affected by the location of the electromechanical modes. Rather than with specified values, it is sufficient that electromechanical modes are placed in a suitable region in the complex s-plane to ensure enough damping effects on low frequency oscillations. Power system stabilizers (PSSs) have been widely used to increase the damping ratios of electromechanical modes to suppress low frequency oscillations. The lead-lag type PSS using theory of phase compensation in fre-

Paper Submitted 06/16/05, Accepted 10/31/05. Author for Correspondence: Chi-Jui Wu. E-mail: cjwu@mouse.ee.ntust.edu.tw.

*Lecture, Department of Electrical Engineering, Ming-Hsin University of Science and Technology.

**Professor, Department of Electrical Engineering, National Taiwan University of Science and Technology, Taipei, Taiwan, R.O.C. quency domain was a conventional compensator [7, 911, 19]. Recently, design technology has been focused on the question of how to tune the parameters of PSSs in order to obtain optimal dynamic stability characteristics. Those approaches include the optimization method using eigenvalue analysis [8], genetic design using simulated annealing optimization algorithms [2], probabilistic approach [17], Tabu search algorithm [4], particleswarm-optimization technique [3], and the genetic algorithm [1].

The method of hybrid differential evolution (HDE) is one of the best evolutionary algorithms for solving non-linear optimization problems [12, 14]. A lot of literatures have recoded the HDE algorithm applications. They have been applied to the optimal control problem of a bio-process system [6]. Estimating the kinetic model parameters using HDE was presented in [18]. This method was also employed for plant scheduling and planning to solve the decision-making problems of the manufacturing industry [13]. The improved HDE method for distribution systems has been used to reduce power loss and enhance the voltage profile [16]. This method may determine the optimal capacitor location of a radial distribution feeder [15].

The HDE method is applied in this paper to tune the lead-lag type PSSs. The speed feedback scheme is applied, considering the implementation requirement. The optimal design technology of the HDE is used to move some lower damping electromechanical modes to or near a region in the left part of the complex plane bounded by a line with a given negative real value. The objective function is selected to ensure the real parts of electromechanical modes. At the end of the iterative procedures, all of the electromechanical modes will be moved to or near this region if the objective function can converge to a value. In the conventional optimal approaches, the design works under several operating conditions should be done. The design result of each operating condition is obtained. A better one is chosen from those design results. Using the benefit in choosing the objective function in the HDE approach, the design 
results, where only one operating condition is considered and where several operating conditions are considered at the same time, are compared. From the design and simulation results of a multi-machine power system, the proposed PSSs can let the generators have enough oscillation damping effects when there are tripping line disturbances.

\section{HYBRID DIFFERENTIAL EVOLUTION}

A nonlinear optimization problem can be expressed as

$$
\text { Minimize } M(\boldsymbol{X})
$$

Subject to

$$
\begin{aligned}
& g_{k}(\boldsymbol{X}) \leq 0 \quad k=1, \ldots, n_{g} \\
& h_{k}(\boldsymbol{X})=0 \quad k=1, \ldots, n_{h}
\end{aligned}
$$

where $M(X)$ : objective function of variable vector $\boldsymbol{X}$,

$$
\begin{gathered}
\boldsymbol{X}=\left[\boldsymbol{X}_{1}, \boldsymbol{X}_{2}, \ldots, \boldsymbol{X}_{j}, \ldots, \boldsymbol{X}_{D}\right]^{T} \\
g_{k}(\boldsymbol{X}): \text { inequality constraints. } \\
h_{k}(\boldsymbol{X}) \text { : equality constraints. }
\end{gathered}
$$

The differential evolution is a parallel direct search method for minimizing nonlinear and non-differential objective functions. The fitness of an offspring is determined by one-to-one competition with the corresponding parent. The solution procedures are given as follows.

\section{Step 1. Initialization}

Several initial populations $\boldsymbol{X}_{i}^{0}, i=1,2, \ldots, N_{P}$ are randomly selected. They should cover the entire search space uniformly. The elements of each individual $\boldsymbol{X}_{i}^{0}$ are given by

$$
\begin{aligned}
& X_{j i}^{0}=X_{j}^{\min }+\rho_{i}\left(X_{j}^{\max }-X_{j}^{\min }\right), \\
& j=1,2, \ldots, D, i=1,2, \ldots, N_{p}
\end{aligned}
$$

where $\rho_{i} \in[0,1]$ is a random number, and $N_{P}$ is the population size. $X_{j}^{\min }$ and $X_{j}^{\max }$ are the lower and upper bounds of the variable $X_{j}$, respectively.

\section{Step 2. Mutation operation}

At generation $G$, each mutant vector is generated based on the corresponding present individual $\boldsymbol{X}_{i}^{G}$ by

$$
\boldsymbol{U}_{i}^{G+1}=\boldsymbol{X}_{i}^{G}+F\left(\boldsymbol{X}_{r 1}^{G}-\boldsymbol{X}_{r 2}^{G}\right), i=1,2, \ldots, N_{p}
$$

where $i \neq r 1, i \neq r 2$, and $r 1, r 2 \in\left\{1,2, \ldots N_{P}\right\} . F \in[0$, 1] is a scalar factor. $\boldsymbol{X}_{r 1}^{G}$ and $\boldsymbol{X}_{r 2}^{G}$ are two randomly selected individuals.

\section{Step 3. Crossover operation}

To extend the diversity of individuals in the next generation, the perturbed individual $\boldsymbol{U}_{i}^{G+1}=\left[U_{1 i}^{G+1}\right.$, $\left.U_{2 i}^{G+1}, \ldots, U_{j i}^{G+1}, \ldots, U_{D i}^{G+1}\right]^{T}$ and the present individual $\boldsymbol{X}_{i}^{G}$ $=\left[X_{1 i}^{G}, X_{2 i}^{G}, \ldots, X_{j i}^{G}, \ldots, X_{D i}^{G}\right]^{T}$ are mixed to yield the trial vector

$$
\hat{\boldsymbol{U}}_{i}^{G+1}=\left[\hat{U}_{1 i}^{G+1}, \hat{U}_{2 i}^{G+1}, \cdots, \hat{U}_{j i}^{G+1}, \cdots, \hat{U}_{D i}^{G+1}\right]^{T}
$$

where

$$
\begin{aligned}
& \hat{U}_{j i}^{G+1}=\left\{\begin{array}{c}
X_{j i}^{G}, \text { if a random number }>C_{R} \\
U_{j i}^{G+1}, \text { otherwise }
\end{array}\right. \\
& j=1,2, \ldots, D, i=1,2, \ldots, N_{P}
\end{aligned}
$$

where $D$ is also the number of genes. $C_{R} \in[0,1]$ is the crossover factor and must be set by the user.

\section{Step 4. Evaluation and selection}

The parent is replaced by its offspring in the next generation if the fitness of the latter is better. Contrarily, the parent is retained. The first step is one-to-one competition. The next step chooses the best individual, $\boldsymbol{X}_{b}^{G+1}$ in the population. That is

$$
\begin{aligned}
& \boldsymbol{X}_{i}^{G+1}=\arg -\min \left\{M\left(\boldsymbol{X}_{i}^{G}\right), M\left(\hat{\boldsymbol{U}}_{i}^{G+1}\right)\right\}, \\
& i=1,2, \ldots, N_{P} \\
& \boldsymbol{X}_{b}^{G+1}=\arg -\min \left\{M\left(\boldsymbol{X}_{i}^{G+1}\right)\right\}, \\
& i=1,2, \ldots, N_{P}
\end{aligned}
$$

where arg-min means the argument of the minimum.

The above steps are repeated until the maximum iteration number or the desired fitness is obtained. In general, a faster descent usually leads to a local minimum or a premature convergence. Conversely, diversity guarantees a high probability of obtaining the global optimum. The trade-off can be obtained by slightly lowering the scaling factor $F$ and by increasing 
the population size $N_{P}$. However, more computation time is required. The migrant and accelerated operations in HDE are used to overcome the local minimum solution and time consumption. The migrant and accelerating operations are inserted in the differential evolution.

\section{Step 5. Migrant operation if necessary}

For increasing search space exploration, a migration operation is introduced to regenerate a diverse population of individuals. The migrant individuals are selected on a "best individual" basis $\boldsymbol{X}_{b}^{G+1}$. The $j^{\text {th }}$ gene of $\boldsymbol{X}_{i}$ is regenerated by

$X_{j i}^{G+1}=\left\{\begin{array}{l}X_{j b}^{G+1}+\rho_{1}\left(X_{j}^{\min }-X_{j b}^{G+1}\right), \text { if a ramdom number } \rho_{2}<\frac{X_{j b}^{G+1}-X_{j}^{\min }}{X_{j}^{\max }-X_{j}^{\min }} \\ X_{j b}^{G+1}+\rho_{1}\left(X_{j}^{\max }-X_{j b}^{G+1}\right), \text { otherwise }\end{array}\right.$

where $\rho_{1}$ and $\rho_{2}$ are randomly generated numbers uniformly distributed in $[0,1]$. The migrant population will not only become a set of newly promising solutions, but also avoid the local minimum trap.

The migrant operation is performed only if a measure fails to match the desired population diversity tolerance. The measure in this study is defined as

$$
u=\frac{\left|\sum_{\substack{i=1 \\ i \neq b}}^{N_{P}} \sum_{j=1}^{D}\right|}{D\left(N_{P}-1\right)}<\varepsilon_{1}
$$

where

$$
\eta_{j i}=\left\{\begin{array}{l}
1, \text { if a gene div ersity }\left|\frac{X_{j i}^{G+1}-X_{j b}^{G+1}}{X_{j b}^{G+1}}\right|>\varepsilon_{2} \\
0, \text { otherwise }
\end{array}\right.
$$

parameters $\varepsilon_{1} \in[0,1]$ and $\varepsilon_{2} \in[0,1]$ express the desired tolerance of the population diversity and the gene diversity with regard to the best individual, respectively. Here $\eta_{j i}$ is defined as an index of the gene diversity. A zero $\eta_{j i}$ means that the $j^{\text {th }}$ gene of the $i^{\text {th }}$ individual is close to the $j^{\text {th }}$ gene of the best individual. If the degree of population diversity $u$ is smaller than $\varepsilon_{1}$, the HDE performs migration to generate a new population to escape the local point. Otherwise, HDE breaks off the migration, which maintains an ordinary search direction.

\section{Step 6. Accelerated operation if necessary}

When the fitness in the present generation is no longer improved using the mutation and crossover operations, a descent method is then applied to push the present best individual toward a better point. Thus, the acceleration operation can be expressed as

$\hat{\boldsymbol{X}}_{b}^{G+1}=\left\{\begin{array}{l}\boldsymbol{X}_{b}^{G+1}, \text { if a objective function } M\left(\boldsymbol{X}_{b}^{G+1}\right)<M\left(\boldsymbol{X}_{b}^{G}\right) \\ \boldsymbol{X}_{b}^{G+1}-\alpha \nabla M\left(\boldsymbol{X}_{b}^{G+1}\right), \text { otherwise }\end{array}\right.$

The gradient of the objective function, $\nabla M\left(X_{b}^{G+1}\right)$, can be approximately calculated with a finite difference. The step size $\alpha \in(0,1]$ is determined according to the decent property. Firstly, $\alpha$ is set to unity. The objective function $M\left(\hat{\boldsymbol{X}}_{b}^{G+1}\right)$ is then compared with $M\left(\boldsymbol{X}_{b}^{G+1}\right)$. If the decent property is achieved, $\hat{\boldsymbol{X}}_{b}^{G+1}$ becomes a can didate in the next generation, and is added into this population to replace the worst individual. On the other hand, if the decent requirement fails, the step size is reduced, for example, 0.5 or 0.7 . The decent search method is repeated to find the optimal $\hat{\boldsymbol{X}}_{b}^{G+1}$, called $\boldsymbol{X}_{b}^{N}$, at the $(G+1)^{\text {th }}$ generation. This result shows the objective function $M\left(\boldsymbol{X}_{b}^{N}\right)$ should be at least equal or smaller than $M\left(\boldsymbol{X}_{b}^{G+1}\right)$.

\section{PSSS DESIGN}

\section{Power system description}

Determining the parameters of PSSs for an Ngenerator power system should consider various loading conditions. When a linearized time-invariant system is considered, the equations of generator $i$ in the two-axis model are expressed by

$$
\begin{aligned}
& \dot{\boldsymbol{x}}_{i}(\boldsymbol{t})=\boldsymbol{A}_{i i} \boldsymbol{x}_{i}(\boldsymbol{t})+\sum_{j=1, j \neq i}^{N} \boldsymbol{A}_{i j} \boldsymbol{x}_{j}(\boldsymbol{t})+\boldsymbol{B}_{i i} \boldsymbol{u}_{i}(\boldsymbol{t}) \\
& i=1,2, \ldots, N
\end{aligned}
$$

where $\boldsymbol{x}_{i}(t)=\left[\begin{array}{llllll}\Delta E_{d i}^{\prime} & \Delta E_{q i}^{\prime} & \Delta \omega_{i} & \Delta \delta_{i} & \Delta E_{F D i} & \Delta V_{S i}\end{array}\right]^{T}$ is the state vector, $\Delta E_{d i}^{\prime}$ and $\Delta E_{q i}^{\prime}$ are the $d$-axis and $q$-axis transient voltages, respectively, and $\Delta \omega_{i}$ and $\Delta \delta_{i}$ are the rotor speed and angle, respectively. $\Delta E_{F D i}$ is the field voltage, $\Delta V_{S i}$ is the output signal of stabilizing transformer. The diagram of static excitation is given signal in Figure 1. 


\section{Lead-lag PSS}

The conventional lead-lag phase compensation PSSs are considered as shown in Figure 2. The transfer function is

$$
u(s)=K_{S} \frac{s T_{5}}{1+s T_{5}}\left(\frac{\left(1+s T_{1}\right)\left(1+s T_{3}\right)}{\left(1+s T_{2}\right)\left(1+s T_{4}\right)}\right) \Delta \omega(s)
$$

If the washout time constant, $T_{5}$, is given, the remaining parameters, $K_{S}, T_{1}, T_{2}, T_{3}$, and $T_{4}$, are to be determined by the HDE. The differential equations of the multi-machine power system are linearized under an operating point, the eigenvalues are computed, and the objective functions are evaluated. Only the unstable and lightly damped electromechanical modes need to be shifted.

\section{Objective function}

For a given negative real constant, $\sigma_{0}$, the objective functions is selected to be

$$
M=\sum_{j=1}^{n p} \sum_{\sigma_{i, j} \geq \sigma_{0}}\left(\sigma_{0}-\sigma_{i, j}\right)^{2}
$$

where $n p$ is the number of operating points considered simultaneously in the design process, and $\sigma_{i, j}$ is the real part of the $i^{\text {th }}$ electromechanical mode under the $j^{\text {th }}$ operating condition. The relative stability condition is determined by $\sigma_{0}$. This will move all of the electromechanical modes to or rear the sector characterized by $\sigma_{i, j} \leq \sigma_{0}$ as shown in Figure 3. The flowchart of PSS design is shown in Figure 4. It is necessary to mention here that only the lightly damped electromechanical

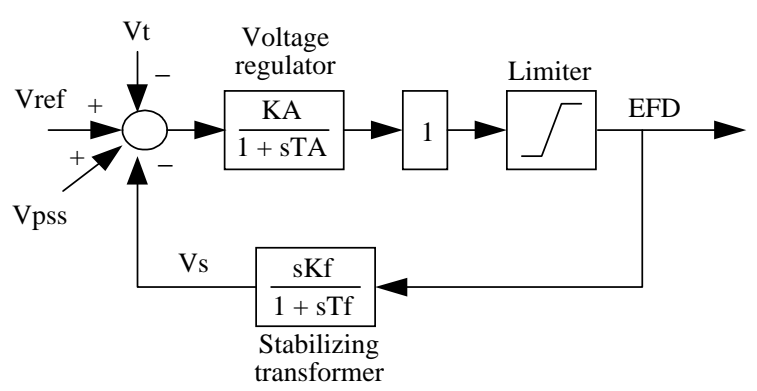

Fig. 1. Block diagram of static excitation system.

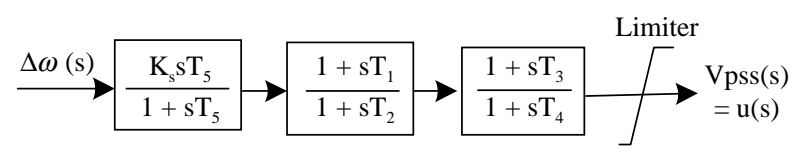

Fig. 2. Block diagram of lead-lag phase compensation power system stabilizer. modes are relocated.

\section{EXAMPLE: A MULTI-MACHINE SYSTEM}

Consider a multi-machine system as shown in Figure 5, where bus 1 is assumed to be an infinite bus. For the simplicity of the system model, generators 2-6 are equipped with static exciters as shown in Figure 1. Four static loads are connected to bus 8,11, 13 and, 14, respectively. The system data are given in Appendix.

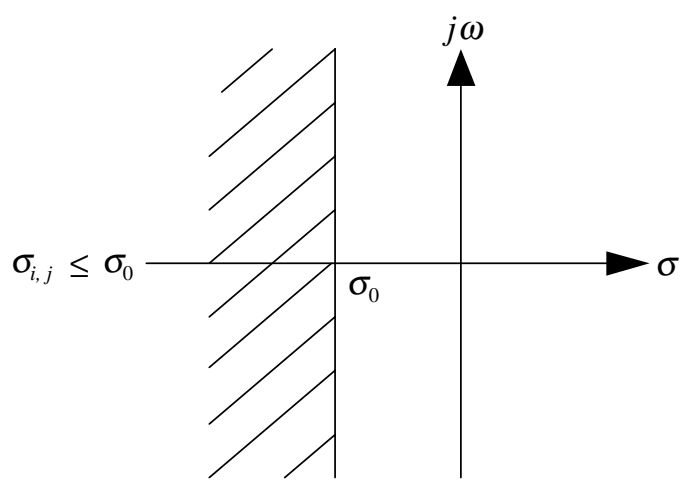

Fig. 3. A region where $\sigma_{i, j} \leq \sigma_{0}$.

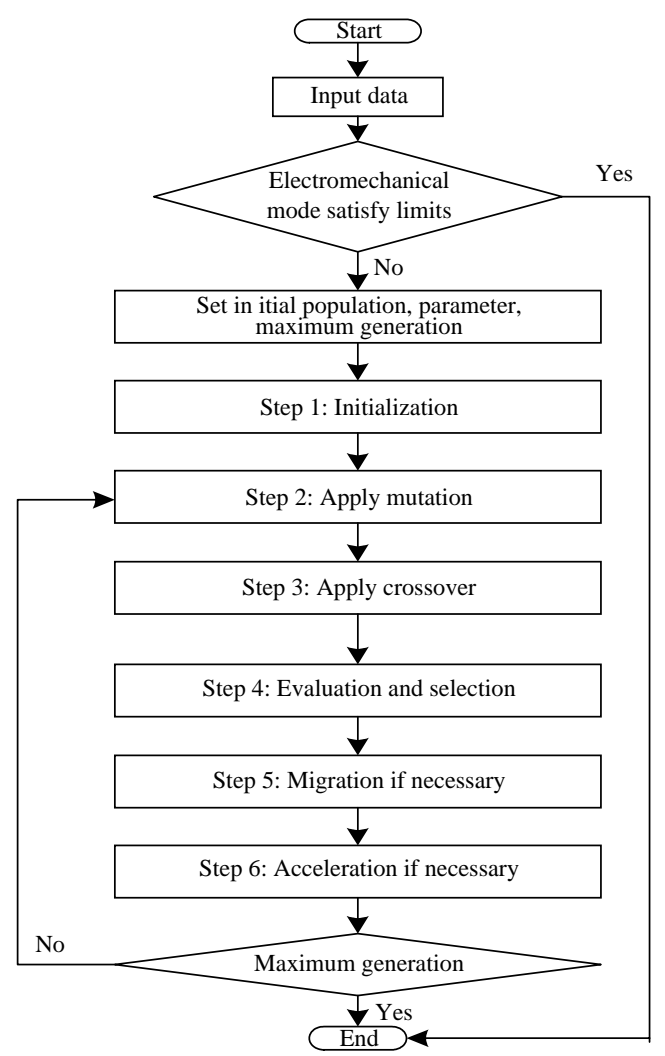

Fig. 4. Flowchart of HDEPSS. 
For the system in Figure 5, the output active power and terminal voltage of the system for five operating conditions are given in Table 1. But in scheme 4 and scheme 5 , the line from bus 12 to bus 14 is removed.

Five control schemes are compared.

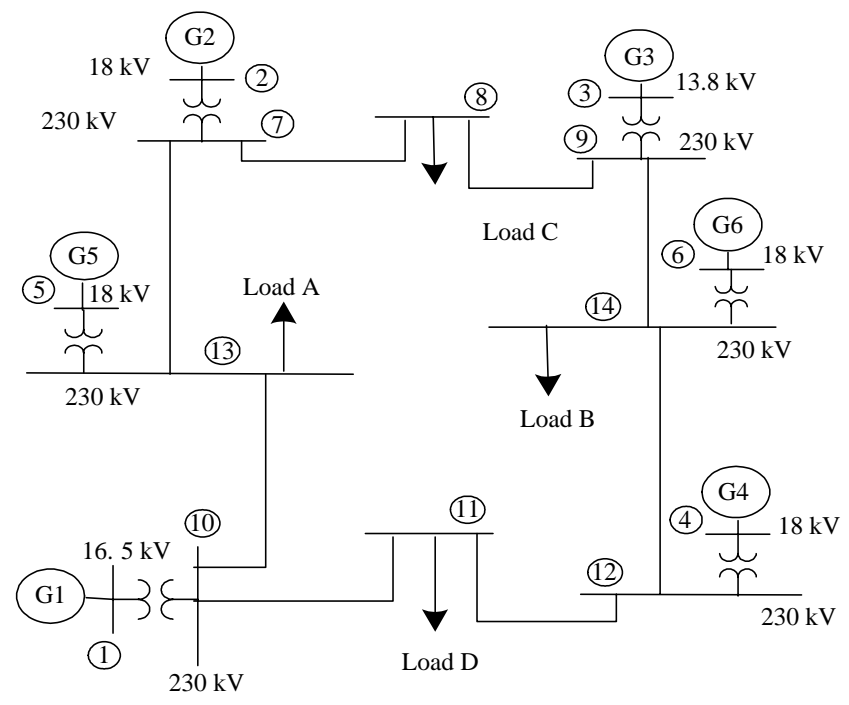

Fig. 5. A multi-machine power system diagram.
Scheme 1: Without PSS.

Scheme 2: Generator 2, 5, and 6 are equipped with the conventional PSSs, whose parameter values are designed by phase compensation and root locus analysis and given in the second column of Table 2 [11].

Scheme 3: Generator 2 and 6 are equipped with HDE PSSs. The parameter values of the PSSs are designed under operating condition 1 only.

Scheme 4: Generator 2, 5, and 6 are equipped with HDE PSSs. The parameter values of the PSSs are designed under operating condition 1 only.

Scheme 5: Generator 2, 5, and 6 are equipped with HDE PSSs. The parameter values of the PSSs are designed when 5 operating conditions are considered at the same time.

For the system without PSSs under the five operating conditions, the electromechanical modes are tabulated in the second row of Table 3. The damping is inadequate. Especially, the electromechanical modes of generators 2, 5, and 6 have bigger real part values, which mean the system has less damping forces. To improve the system damping effect, those modes should

Table 1. Five operating conditions

\begin{tabular}{|c|c|c|c|c|c|c|c|c|c|c|c|}
\hline & & \multicolumn{2}{|c|}{ G2 } & \multicolumn{2}{|c|}{ G3 } & \multicolumn{2}{|c|}{ G4 } & \multicolumn{2}{|c|}{ G5 } & \multicolumn{2}{|c|}{ G6 } \\
\hline $\begin{array}{l}\text { Operating } \\
\text { condition }\end{array}$ & Loads (pu) & $\begin{array}{c}P_{g} \\
(\mathrm{pu})\end{array}$ & $\begin{array}{c}V_{t} \\
(\mathrm{pu})\end{array}$ & $\begin{array}{c}P_{g} \\
(\mathrm{pu})\end{array}$ & $\begin{array}{c}V_{t} \\
(\mathrm{pu})\end{array}$ & $\begin{array}{c}P_{g} \\
(\mathrm{pu})\end{array}$ & $\begin{array}{c}V_{t} \\
(\mathrm{pu})\end{array}$ & $\begin{array}{c}P_{g} \\
(\mathrm{pu})\end{array}$ & $\begin{array}{c}V_{t} \\
(\mathrm{pu})\end{array}$ & $\begin{array}{c}P_{g} \\
(\mathrm{pu})\end{array}$ & $\begin{array}{c}V_{t} \\
(\mathrm{pu})\end{array}$ \\
\hline 1 & $\begin{array}{l}\mathbf{S}_{\mathbf{L A}}=2.5+j 1.0 \\
\mathbf{S}_{\mathbf{L B}}=1.8+j 0.6 \\
\mathbf{S}_{\mathbf{L C}}=1+j 0.35 \\
\mathbf{S}_{\mathbf{L D}}=1+j 0.35\end{array}$ & 1.63 & 1.03 & 0.85 & 1.03 & 1.32 & 1.03 & 1.32 & 1.03 & 1.32 & 1.03 \\
\hline 2 & $\begin{array}{l}\mathbf{S}_{\mathbf{L A}}=3+j 1.2 \\
\mathbf{S}_{\mathbf{L B}}=2.16+j 0.72 \\
\mathbf{S}_{\mathbf{L C}}=1.2+j 0.42 \\
\mathbf{S}_{\mathbf{L D}}=1.2+j 0.42\end{array}$ & 1.96 & 1.04 & 1.02 & 1.04 & 1.58 & 1.04 & 1.58 & 1.04 & 1.58 & 1.04 \\
\hline 3 & $\begin{array}{l}\mathbf{S}_{\mathbf{L A}}=1+j 0.4 \\
\mathbf{S}_{\mathbf{L B}}=0.72+j 0.24 \\
\mathbf{S}_{\mathbf{L C}}=0.4+j 0.14 \\
\mathbf{S}_{\mathbf{L D}}=0.4+j 0.14\end{array}$ & 0.65 & 1.01 & 0.34 & 1.01 & 0.53 & 1.01 & 0.53 & 1.01 & 0.53 & 1.01 \\
\hline 4 & $\begin{array}{l}\mathbf{S}_{\mathbf{L A}}=2.5+j 1.0 \\
\mathbf{S}_{\mathbf{L B}}=1.8+j 0.6 \\
\mathbf{S}_{\mathbf{L C}}=1+j 0.35 \\
\mathbf{S}_{\mathbf{L D}}=1+j 0.35\end{array}$ & 1.63 & 1.03 & 0.85 & 1.03 & 1.32 & 1.03 & 1.32 & 1.03 & 1.32 & 1.03 \\
\hline 5 & $\begin{array}{l}\mathbf{S}_{\mathbf{L A}}=2.5+j 1.0 \\
\mathbf{S}_{\mathbf{L B}}=1.8+j 0.6 \\
\mathbf{S}_{\mathbf{L C}}=1+j 0.35 \\
\mathbf{S}_{\mathbf{L D}}=1+j 0.35\end{array}$ & 1.63 & 1.03 & 1.28 & 1.03 & 1.32 & 1.03 & 1.32 & 1.03 & 1.98 & 1.03 \\
\hline
\end{tabular}


Table 2. The parameters of PSSs

\begin{tabular}{cccccccc}
\hline \multirow{5}{*}{ Scheme 2 } & & $K_{S}$ & $\begin{array}{c}T_{1} \\
(\mathrm{sec})\end{array}$ & $\begin{array}{c}T_{2} \\
(\mathrm{sec})\end{array}$ & $\begin{array}{c}T_{3} \\
(\mathrm{sec})\end{array}$ & $\begin{array}{c}T_{4} \\
(\mathrm{sec})\end{array}$ & $\begin{array}{c}T_{5} \\
(\mathrm{sec})\end{array}$ \\
& G2 & 25 & 0.25 & 0.05 & 0.5 & 0.06 & 0.5 \\
& G5 & 25 & 0.25 & 0.05 & 0.5 & 0.06 & 0.5 \\
& G6 & 25 & 0.25 & 0.05 & 0.5 & 0.06 & 0.5 \\
Scheme 3 & G2 & 38.89 & 0.26 & 1.96 & 0.63 & 0.03 & 5 \\
& G6 & 26.63 & 1.42 & 0.13 & 1.05 & 1.15 & 5 \\
& G2 & 3.02 & 0.8 & 0.35 & 1.85 & 0.19 & 5 \\
& G5 & 37.38 & 0.80 & 1.45 & 0.4 & 0.02 & 5 \\
& G6 & 11.58 & 0.87 & 0.83 & 0.81 & 0.02 & 5 \\
& G2 & 27.18 & 0.04 & 0.99 & 1.96 & 0.01 & 5 \\
& G5 & 4.75 & 1.23 & 1.82 & 1.28 & 0.01 & 5 \\
& G6 & 17.39 & 1.6 & 1.0 & 0.45 & 0.18 & 5 \\
\hline
\end{tabular}

Table 3. Design results of the electromechanical modes

\begin{tabular}{|c|c|c|c|c|c|c|}
\hline $\begin{array}{l}\text { Control } \\
\text { scheme }\end{array}$ & & $\begin{array}{l}\text { Operation } \\
\text { condition } 1\end{array}$ & $\begin{array}{l}\text { Operation } \\
\text { condition } 2\end{array}$ & $\begin{array}{c}\text { Operation } \\
\text { condition } 3\end{array}$ & $\begin{array}{c}\text { Operation } \\
\text { condition } 4\end{array}$ & $\begin{array}{l}\text { Operation } \\
\text { condition } 5\end{array}$ \\
\hline \multirow{5}{*}{ Scheme 1} & $\mathrm{G} 2$ & $-0.57 \pm j 9.96$ & $-0.42 \pm j 9.97$ & $-1.44 \pm j 9.70$ & $-0.35 \pm j 8.33$ & $-0.31 \pm j 8.21$ \\
\hline & G3 & $-1.0 \pm j 14.2$ & $-0.84 \pm j 14.1$ & $-1.93 \pm j 14.1$ & $-1.13 \pm j 14.39$ & $-0.56 \pm j 14.53$ \\
\hline & G4 & $-1.24 \pm j 15.1$ & $-1.08 \pm j 15.3$ & $-2.18 \pm j 14.6$ & $-1.13 \pm j 14.6$ & $-1.14 \pm j 14.35$ \\
\hline & G5 & $-0.97 \pm j 13.0$ & $-0.82 \pm j 13.2$ & $-1.91 \pm j 12.6$ & $-0.52 \pm j 10.9$ & $-0.41 \pm j 10.73$ \\
\hline & G6 & $-0.001 \pm j 6$ & $0.1 \pm j 5.68$ & $-0.39 \pm j 5.88$ & $-0.05 \pm j 5.35$ & $-0.36 \pm j 4.77$ \\
\hline \multirow{5}{*}{ Scheme 2} & G2 & $-1.04 \pm j 12.17$ & $-0.96 \pm j 12.36$ & $-2.07 \pm j 11.74$ & $-0.92 \pm j 7.09$ & $-1.04 \pm j 6.88$ \\
\hline & G3 & $-1.14 \pm j 15.01$ & $-1.07 \pm j 15.25$ & $-2.19 \pm j 14.56$ & $-1.13 \pm j 14.6$ & $-0.7 \pm j 14.53$ \\
\hline & G4 & $-11.83 \pm j 41.63$ & $-11.63 \pm j 42.59$ & $-13.12 \pm j 35.7$ & $-11.83 \pm j 41.75$ & $-11.99 \pm j 40.9$ \\
\hline & G5 & $-1.0 \pm j 14.19$ & $-0.95 \pm j 14.39$ & $-1.87 \pm j 13.88$ & $-1.14 \pm j 13.84$ & $-1.06 \pm j 13.73$ \\
\hline & G6 & $-0.65 \pm j 7.07$ & $-0.62 \pm j 7.24$ & $-1.19 \pm j 6.69$ & $-0.41 \pm j 8.43$ & $-0.32 \pm j 8.28$ \\
\hline \multirow{5}{*}{ Scheme 3} & G2 & $-1.4 \pm j 10.76$ & $-1.36 \pm j 10.85$ & $-2.15 \pm j 10.34$ & $-1.61 \pm j 8.89$ & $-1.21 \pm j 8.62$ \\
\hline & G3 & $-1.48 \pm j 14.12$ & $-1.52 \pm j 14.5$ & $-2.36 \pm j 13.36$ & $-1.74 \pm j 13.69$ & $-1.7 \pm j 14.4$ \\
\hline & G4 & $-2.29 \pm j 30.75$ & $-2.23 \pm j 31.16$ & $-3.13 \pm j 25.54$ & $-2.87 \pm j 27.79$ & $-2.48 \pm j 29.58$ \\
\hline & G5 & $-1.45 \pm j 14.12$ & $-1.23 \pm j 14.16$ & $-2.19 \pm j 14.06$ & $-1.6 \pm j 14.45$ & $-1.27 \pm j 13.41$ \\
\hline & G6 & $-1.28 \pm j 7.03$ & $-1.38 \pm j 7.24$ & $-1.46 \pm j 6.36$ & $-0.51 \pm j 7.73$ & $-0.51 \pm j 7.46$ \\
\hline \multirow{5}{*}{ Scheme 4} & G2 & $-1.52 \pm j 11.83$ & $-1.49 \pm j 12.05$ & $-2.3 \pm j 11.13$ & $-3.16 \pm j 10.82$ & $-2.97 \pm j 10.66$ \\
\hline & G3 & $-17.55 \pm j 25.1$ & $-1.76 \pm j 25.62$ & $-10.84 \pm j 17.25$ & $-17.21 \pm j 24.15$ & $-16.84 \pm j 22.4$ \\
\hline & G4 & $-17.74 \pm j 31.7$ & $-17.69 \pm j 32.37$ & $-15.59 \pm j 20.71$ & $-19.45 \pm j 27.47$ & $-19.12 \pm j 30.79$ \\
\hline & G5 & $-1.87 \pm j 14.66$ & $-1.78 \pm j 14.88$ & $-2.45 \pm j 13.86$ & $-1.99 \pm j 14.77$ & $-1.81 \pm j 14.44$ \\
\hline & G6 & $-2.35 \pm j 7.97$ & $-2.33 \pm j 8.4$ & $-2.06 \pm j 6.01$ & $-0.61 \pm j 8.17$ & $-0.61 \pm j 8.13$ \\
\hline \multirow{5}{*}{ Scheme 5} & G2 & $-1.39 \pm j 11.58$ & $-1.37 \pm j 11.78$ & $-2.07 \pm j 10.91$ & $-1.68 \pm j 8.84$ & $-1.31 \pm j 8.24$ \\
\hline & G3 & $-1.64 \pm j 19.98$ & $-1.6 \pm j j 20.25$ & $-2.36 \pm j 17.87$ & $-1.74 \pm j 17.78$ & $-1.47 \pm j 18.46$ \\
\hline & G4 & $-7.02 \pm j 14.05$ & $-7 \pm j 14.12$ & $-5.68 \pm j 14.65$ & $-6.9 \pm j 14.24$ & $-6.21 \pm j 14.16$ \\
\hline & G5 & $-1.82 \pm j 14.32$ & $-1.74 \pm j 14.53$ & $-2.32 \pm j 13.61$ & $-2.11 \pm j 14.31$ & $-1.94 \pm j 13.98$ \\
\hline & G6 & $-1.41 \pm j 7.21$ & $-1.5 \pm j 7.47$ & $-1.35 \pm j 6.47$ & $-0.95 \pm j 8.01$ & $-1.29 \pm j 8.23$ \\
\hline
\end{tabular}


Table 4. Design results of the objective functions

\begin{tabular}{ccccccc}
\hline & $\begin{array}{c}\text { Operation } \\
\text { condition 1 }\end{array}$ & $\begin{array}{c}\text { Operation } \\
\text { condition 2 }\end{array}$ & $\begin{array}{c}\text { Operation } \\
\text { condition 3 }\end{array}$ & $\begin{array}{c}\text { Operation } \\
\text { condition 4 }\end{array}$ & $\begin{array}{c}\text { Operation } \\
\text { condition 5 }\end{array}$ & $\begin{array}{c}\text { Operation } \\
\text { conditions 1-5 }\end{array}$ \\
\hline Scheme 1 & 2.24 & 4.80 & 1.24 & 4.66 & 4.92 & 17.86 \\
Scheme 2 & 1.31 & 1.56 & 0.1 & 1.8 & 2.42 & 7.19 \\
Scheme 3 & 0.06 & 0.1 & 0.0016 & 0.98 & 0.98 & 2.12 \\
Scheme 4 & 0 & 0.0001 & 0 & 0.79 & 0.79 & 1.58 \\
Scheme 5 & 0.02 & 0.012 & 0.023 & 0.3 & 0.08 & 0.435 \\
\hline
\end{tabular}

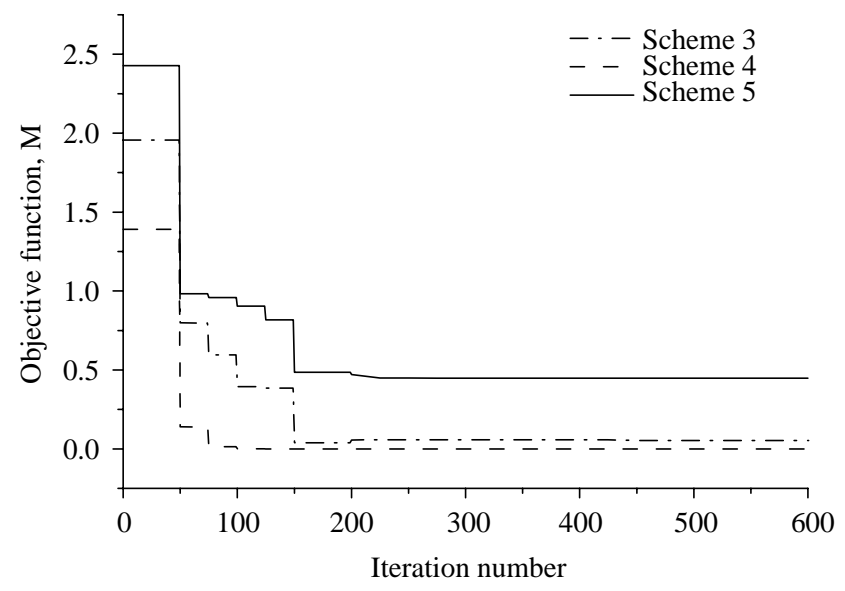

Fig. 6. Convergent characteristics of objective functions.

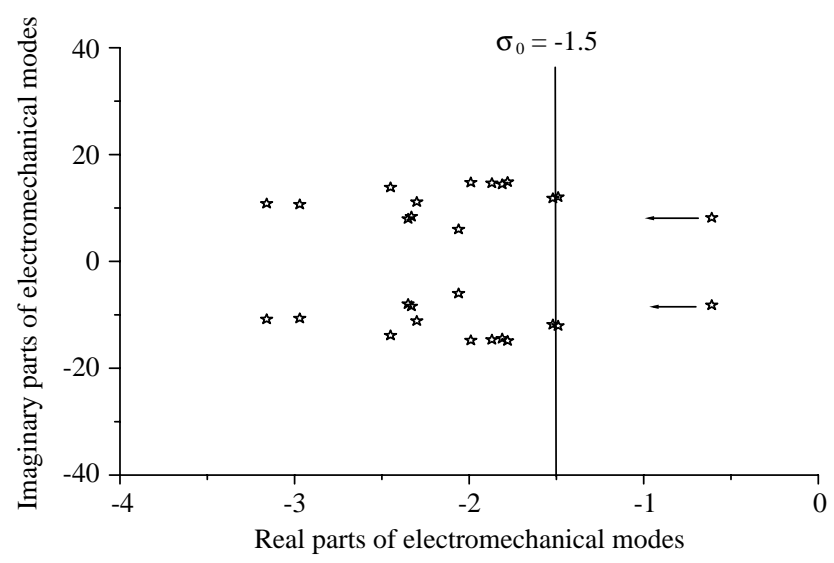

Fig. 7. Location of electromechanical modes of the system with scheme 4 under operation conditions 1-5.

be moved toward certain desirable locations.

In the design of schemes $3-4$, it is selected that $\sigma_{0}$ $=-1.5$. All of objective functions have converged to approach zero as revealed in Figure 6, which means that all electromechanical modes have been moved to or near the designated region. The design results of PSSs are given in the columns 3-7 of Table 2 . The electrome-

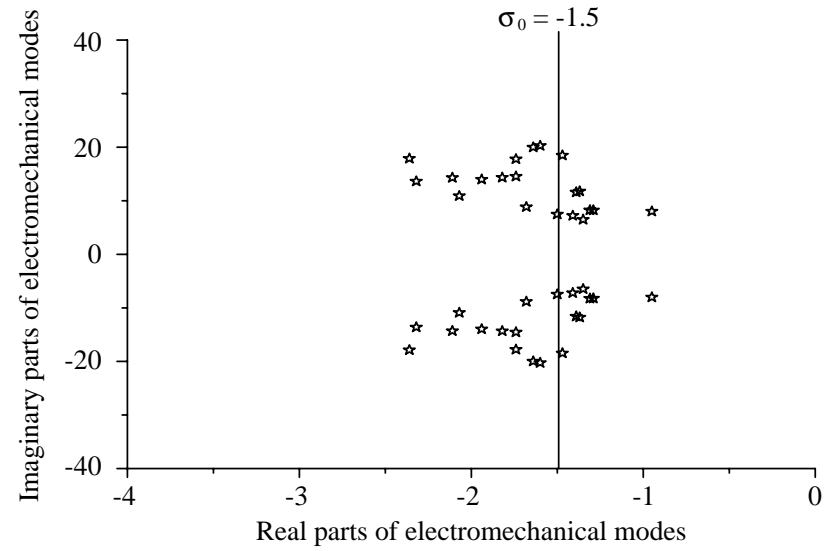

Fig. 8. Location of electromechanical modes of the system with scheme 5 under operation conditions 1-5.

chanical modes of five operating conditions are tabulated in Table 3. Since scheme 3 is designed under the operating condition 1 only, the real part of each electromechanical mode approaches -1.5 in this operating condition. However, this is not true in operating conditions 4 and 5. Although scheme 4 is also designed under operating condition 1 only, it gives better damping effect. But the damping conditions in operating conditions 4 and 5 are still not satisfied. Since in the design of scheme 5, five operating conditions are considered at the same time, the light damping electromechanical modes have been moved to approach the designated region for all operating conditions.

With the designed PSSs, the values of objective functions are given in Table 4. Since all of five operating conditions are considered, the objective function of the system with scheme 5 is smallest. This means that this scheme could give better damping effect under a wide range of operating condition. Figures 7 and 8 show location of electromechanical modes of the system with scheme 4 or 5 under operation conditions 1-5.

In the time domain simulations, nonlinear differential equations must be used to examine the damping effect of PSSs. The tripping of line 7-13 is used as a 

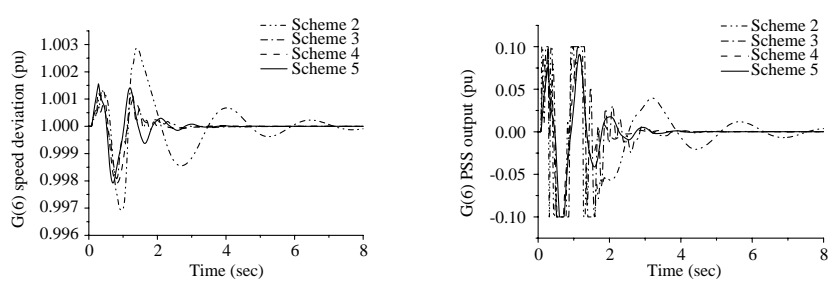

Fig. 9. Responses of generator 6 under operation condition 1 subjected to large disturbance.
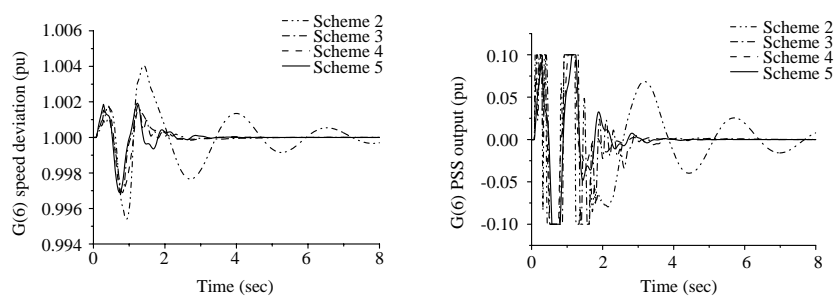

Fig. 10. Responses of generator 6 under operation condition 2 subjected to large disturbance.
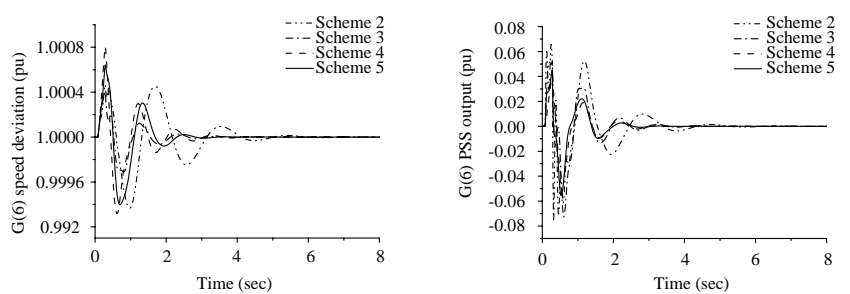

Fig. 11. Responses of generator 6 under operation condition 3 subjected to large disturbance.

larger disturbance. Simulation results of generator 6 are given in Figures 9-13 for the system under five operating conditions. The system with scheme 5 is better if five operating conditions are considered at the same time.

\section{CONCLUSION}

A novel pole placement design approach of the lead lag phase compensation power system stabilizers has been successfully achieved by using the hybrid differential evolution method. A multi-machine system is used as an example to demonstrate the developed method and reveal the convergent procedures. Several control schemes are given and one of them can give better design results. The chosen region to assign the real part of electromechanical modes could be relatively important in the design. It wants to guarantee a system with enough damping effects on oscillations over wide
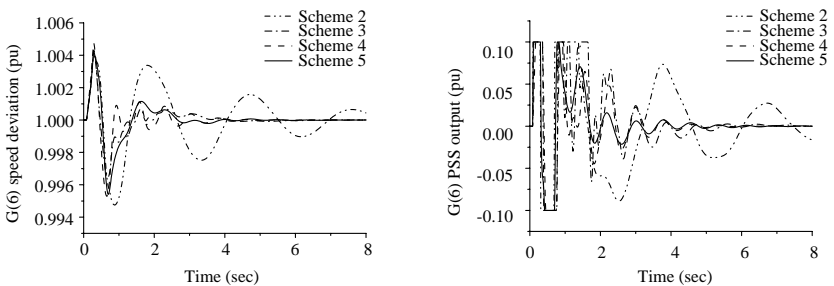

Fig. 12. Responses of generator 6 under operation condition 4 subjected to large disturbance.
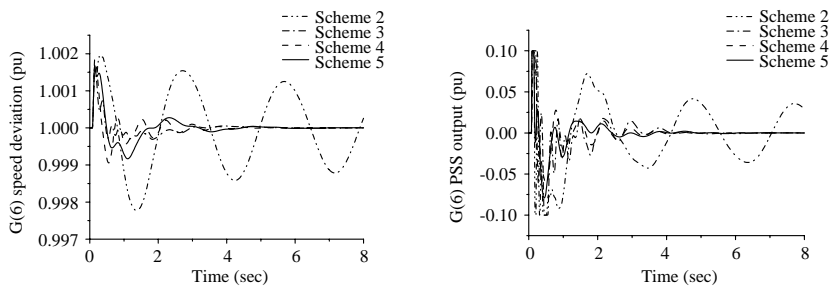

Fig. 13. Responses of generator 6 under operation condition 5 subjected to large disturbance.

range of loading conditions. From the simulation results, the HDE gives a good method in tuning power system stabilizers to improve system dynamic stability.

\section{ACKNOWLEDGMENTS}

This paper is supported partly by the National Science Council of ROC, NSC 93-2213-E-011-082.

\section{REFERENCES}

1. Abdel-Magid, Y.L. and Abido, M.A., "Optimal Multiobjective Design of Robust Power System Stabilizers Using Genetic Algorithms," IEEE Transaction on Power Systems, Vol. 18, No. 3, pp. 1125-1132 (2003).

2. Abido, M.A., "Robust Design of Multimachine Power System Stabilizers Using Simulated Annealing," IEEE Transactions on Energy Conversion, Vol. 15, No. 3, pp. 297-304 (2000).

3. Abido, M.A., "Optimal Design of Power-System Stabilizers Using Particle Swarm Optimization," IEEE Transactions on Energy Conversion, Vol. 17, No. 3, pp. 406413 (2002).

4. Abido, M.A. and Abdel-Magid, Y.L., "Robust Design of Multimachine Power System Stabilisers Using Tabu Search Algorithm," IEE Proceedings Generation, Transmission and Distribution, Vol. 147. No. 6, pp. 387-394 (2000).

5. Anderson, P.M. and Fouad, A.A., Power System Control and Stability, Iowa State University Press, Ames, IA (1977). 
6. Chiou, J.P. and Wang, F.S., "A Hybrid Method of Differential Evolution with Application to Optimal Control Problems of a Bioprocess System," Proceeding of the IEEE on Evolutionary Computation Conference, Anchorage, AK, pp. 627-632 (1998).

7. deMello, F.P. and Concordia, C., "Concept of Synchronous Machine Stability as Affected by Excitation Control," IEEE Transactions on Power Apparatus and Systems, Vol. 88, No. 4, pp. 316-329 (1969).

8. Hong, Y.Y. and Wu, W.C., "A New Approach Using Optimization for Tuning Parameters of Power System Stabilizers," IEEE Transactions on Energy Conversion, Vol. 14, No. 3, pp. 780-786 (1999).

9. Hsu, Y.Y. and Su, C.C., "Application of Power System Stabilizer on a System with Pumped Storage Plant," IEEE Transactions on Power System, Vol. 3, No. 1, pp. 80-86 (1988).

10. Kundur, P., Klein, M., Rogers, G.J., and Zywno, M.S., "Application of Power System Stabilizers for Enhancement of Overall System Stability," IEEE Transactions on Power System, Vol. 4, No. 2, pp. 614-626 (1989).

11. Larsen, E.V. and Swann, D.A., "Applying Power System Stabilizers Part I, II, III," IEEE Transactions Power Apparatus System, Vol. PAS-100, pp. 3017-3046 (1981).

12. Li, Y.C., Wang, F.S., and Hwang, K.S., "A Hybrid Method of Evolutionary Algorithms for Mixed-Integer Nonlinear Optimization Problems," Proceedings of the Congress on Evolutionary Computation, Washington, D. C., pp. 2159-2166 (1999).

13. Lin, U.C., Hwang, K.S., and Wang, F.S., "Plant Scheduling and Planning Using Mixed-Integer Hybrid Differential Evolution with Multiplier Updating," Proceedings of the Congress on Evolutionary Computation, La Jolla, CA, pp. 593-600 (2000).

14. Lin, Y.C., Hwang, K.S., and Wang, F.S., "Hybrid Differential Evolution with Multiplier Updating Method for Nonlinear Constrained Optimization Problems," Proceedings of the Congress on Evolutionary Computation, Honolulu, HI, pp. 872-877 (2002).

15. Su, C.T. and Lee, C.S., "Modified Differential Evolution Method for Capacitor Placement of Distribution Systems," Proceeding of the Asia Pacific IEEE/PES Transmission and Distribution Conference and Exhibition, Yokohama, Japan, pp. 208-213 (2002).

16. Su, C.T. and Lee, C.S., "Network Reconfiguration of Distribution Systems Using Improved Mixed-Integer Hybrid Differential Evolution," IEEE Transactions on Power Delivery, Vol. 18, No. 3, pp. 1022-1027 (2003).

17. Tse, C.T., Wang, K.W., Chung, C.Y., and Tsang, K.M., "Parameter Optimization of Robust Power System Stabilisers by Probabilistic Approach," IEE Proceedings Generation, Transmission and Distribution, Vol. 147, No. 2, pp. 69-75 (2000).

18. Wang, F.S. and Jang, H.J., "Parameter Estimation of a
Bioreaction Model by Hybrid Differential Evolution," Proceedings of the Congress on Evolutionary Computation, La Jolla, CA, pp. 410-417 (2000).

19. Zhou, E., Malik, O.P., and Hope, G.S., "Design of Stabilizer for a Multimachine Power System Based on the Sensitivity of PSS Effect," IEEE Transactions on Energy Conversion, Vol. 7, No. 3, pp. 606-613 (1992)

\section{APPENDIX}

System data (pu, except as indicated)

The two-axis model describes the generator [5]. The power base is 100MVA.

Generator:

\begin{tabular}{lllllllll}
\hline & $\begin{array}{c}\mathbf{H} \\
(\mathrm{sec})\end{array}$ & $\mathbf{D}$ & $\mathbf{X}_{\mathbf{d}}$ & $\mathbf{X}_{\mathbf{q}}$ & $\mathbf{X}_{\mathbf{d}}^{\prime}$ & $\mathbf{X}_{\mathbf{q}}^{\prime}$ & $\begin{array}{c}\mathbf{T}_{\mathbf{d o}}^{\prime} \\
(\mathrm{sec})\end{array}$ & $\begin{array}{l}\mathbf{T}_{\mathbf{q} \mathbf{o}}^{\prime} \\
(\mathrm{sec})\end{array}$ \\
\hline G 2 & 6.4 & 0 & 0.8958 & 0.8645 & 0.1198 & 0.1969 & 6.0 & 0.535 \\
G 3 & 3.01 & 0 & 1.3125 & 1.2578 & 0.1813 & 0.25 & 5.89 & 0.6 \\
G 4 & 4.69 & 0 & 1.219 & 1.1695 & 0.1619 & 0.215 & 5.95 & 0.573 \\
G 5 & 4.7 & 0 & 1.2166 & 1.1742 & 0.1627 & 0.225 & 5.92 & 0.575 \\
G 6 & 4.71 & 0 & 1.2121 & 1.1789 & 0.1628 & 0.228 & 5.91 & 0.578 \\
\hline
\end{tabular}

Exciter:

\begin{tabular}{ccccc}
\hline KA & $\begin{array}{c}\text { TA } \\
(\mathrm{sec})\end{array}$ & $\begin{array}{c}\text { Kf } \\
(\mathrm{sec})\end{array}$ & $\begin{array}{c}\text { Tf } \\
(\mathrm{sec})\end{array}$ \\
\hline G 2 & 400 & 0.05 & 0.025 & 1.0 \\
G 3 & 400 & 0.05 & 0.025 & 1.0 \\
G 4 & 400 & 0.05 & 0.025 & 1.0 \\
G 5 & 400 & 0.05 & 0.025 & 1.0 \\
G 6 & 400 & 0.05 & 0.025 & 1.0 \\
\hline
\end{tabular}

Excitation voltage limits: $V_{\min }=-7.3 V_{\max }=7.3$ PSS output limits: $V_{\min }=-0.1 V_{\max }=0.1$ PSS washout time constant: $T_{5}=5 \mathrm{sec}$

Transmission lines:

\begin{tabular}{cccccc}
\hline Line No. & From & To & $\mathrm{R}$ & $\mathrm{X}$ & $\mathrm{B} / 2$ \\
\hline 1 & 1 & 10 & 0 & 0.0576 & 0 \\
2 & 2 & 7 & 0 & 0.0625 & 0 \\
3 & 3 & 9 & 0 & 0.0586 & 0 \\
4 & 4 & 12 & 0 & 0.0605 & 0 \\
5 & 5 & 13 & 0 & 0.0605 & 0 \\
6 & 6 & 14 & 0 & 0.0605 & 0 \\
7 & 10 & 13 & 0.01 & 0.085 & 0.088 \\
8 & 7 & 13 & 0.032 & 0.161 & 0.153 \\
9 & 9 & 14 & 0.039 & 0.17 & 0.179 \\
10 & 12 & 14 & 0.017 & 0.092 & 0.079 \\
11 & 7 & 8 & 0.0085 & 0.072 & 0.0745 \\
12 & 8 & 9 & 0.0119 & 0.1008 & 0.1045 \\
13 & 10 & 11 & 0.0085 & 0.072 & 0.0745 \\
\hline
\end{tabular}

